\title{
Three Women in Time: Beatrice Edgell, Josephine Nash Curtis, and Mary Sturt
}

\author{
John H. Wearden ${ }^{1,2, *}$ \\ ${ }^{1}$ School of Psychology, Keele University, Keele, ST5 5BG, UK \\ ${ }^{2}$ Division of Neuroscience and Experimental Psychology, Manchester University, \\ Manchester, M13 9PL, UK
}

Received 2 February 2021; accepted 8 April 2021

\begin{abstract}
This article discusses research on time perception published by three women (Beatrice Edgell, Josephine Nash Curtis, and Mary Sturt) active in the early years of the 20th. Century. Edgell (On time judgment, Am. J. Psychol., 1903) was involved in psychophysical studies on the perception of brief durations, in the tradition of Vierordt and other mostly German authors. Curtis (Duration and the temporal judgment, Am. J. Psychol., 1916) provided detailed reports of introspections from participants performing timing tasks, in the manner of her supervisor, Titchener. Sturt (via the article by Oakden \& Sturt, The development of the knowledge of time in children, Br.J. Psychol., 1922, an article by Sturt herself, Experiments on the estimate of duration, Br. J. Psychol. 1923, and her book The Psychology of Time, 1925) was involved in extensive developmental studies on the understanding of everyday time concepts, such as years, months, and dates, as well as other work involving variations in time judgements as a function of different conditions, such as when receiving painful stimulation.

Keywords

Temporal reproduction, time discrimination, introspection, development of timing, pain and timing
\end{abstract}

\section{Introduction}

This article discusses the work of three women who published research on time perception in the early years of the previous century, between 1903 and 1925. As will be seen later, the research conducted by these women illustrates that work

\footnotetext{
* To whom correspondence should be addressed. E-mail: j.h.wearden@keele.ac.uk
} 
on time perception was as diverse in those days as it is now. Taken together, the research of the three women represents different aspects of timing studies, from laboratory-based psychophysics, through developmental research and anecdotes about passage of time in real life, to an extensive investigation of the phenomenology of time experience. As well as brief biographical information, I provide a discussion of some of the work in their publications and link it to developments that came later.

\section{Beatrice Edgell: The Psychophysics of Time}

Beatrice Edgell (1871-1948) can be credited with a number of notable firsts. When she obtained her doctorate in psychology from Wurzburg in 1901 she became the first British woman to receive a doctorate in psychology and simultaneously the first woman to receive a doctorate from Wurzburg in any subject. She received her undergraduate education at the University of London and the University of Wales, obtaining degrees in Mental and Moral Sciences and Philosophy. In 19001901 she obtained a scholarship from the University of Wales to study psychology under Kulpe in Wurzburg. On returning from Germany she set up a psychological laboratory at Bedford College in London, and in 1927 became Britain's first female professor of psychology at London University. Interest in both philosophy and psychology persisted throughout her career and she was active in professional associations in both subjects, becoming the first woman president of both the British Psychological Society and the Aristotelian Society. For a short appreciation of her life and work, see Valentine (2001), or for a fuller account Valentine (2006).

One of her early publications was an evaluation of four versions of the Wheatstone-Hipp chronoscope (Edgell \& Symes, 1906), used for precisely measuring reaction times, an article sufficiently influential to still be cited thirty years after its publication. Edgell also published work on memory (Edgell, 1924), as well as an introduction to psychology for nurses (Edgell, 1926), and an introduction to ethics for nurses and social workers (Edgell, 1927). As well as the learned bodies mentioned above, she was also active in the British Association for the Advancement of Science, and Valentine (2001) quotes one reaction to a presentation she gave in 1935:

Among the speakers in the Psychology Section was Professor Beatrice Edgell, one of the most learned, if not the most learned, women of the day. [italics in the original]

I discuss here an article on time perception published in 1903. Presumably, the material comes from some of her very earliest work at Bedford College, shortly after her return from Wurzburg. It is also one of the earliest published experimental studies of time perception from a British university, perhaps even the very first.

Edgell's research had two aims. The first was to find the time value that was estimated most accurately. The second was that of finding the subjective midpoint between two time intervals, which she suggested could either be at the 
arithmetic or geometric means of the intervals. For both of these experiments she used a reproduction method, and auditory stimuli, with the auditory stimulus being delivered during the reproduction as well as when presented as a standard. Her 1903 article provides extensive descriptions of the apparatus used and will be of interest to readers curious as to how time measurement was carried out in the early days of psychology.

The general aim of the first experiment was to find the 'indifference point', the time interval which was neither systematically over- or underestimated. This was an important preoccupation of early time researchers, largely due to the work of Vierordt (1868), whose research suggested that short intervals of time tended to be overestimated, and longer ones underestimated, with accurate estimation at some point in the between the shortest and longest values ('Vierordt's Law'). Lejeune and Wearden (2009) discussed Vierordt's work, as well as later research on the same problem, in some detail.

In Edgell's first experiment, three participants (S, B, and Sp) received a range of time intervals from 255 to $6,522 \mathrm{~ms}$, although the number of different durations used varied between participants ( 16 for S, 14 for B, and 13 for Sp), as did the actual time values studied. The number of trials with each time value is not directly given, but information about the overall number of 'experiments' (as individual trials were often called in early studies), suggests 18 trials per time interval for participant $S$ and 32 for the other two participants. Results are shown in Fig. 1.

The upper panel of Fig. 1 shows the length of the reproduction, presumably the mean of all the trials, plotted against the target time to be reproduced. A value greater than 1.0 shows overestimation and a value less than 1.0 underestimation. Obviously, all three participants showed adherence to Vierordt's Law, with the shorter time values being overestimated and the longer ones being estimated more accurately, or even underestimated. The 'indifference point', where the reproduction was accurate was given as $3.33 \mathrm{~s}, 1.94 \mathrm{~s}$, and $1.07 \mathrm{~s}$ for Edgell's three participants, respectively. A common idea is that the indifference point is related to the central tendency of all the intervals presented. This is discussed in some detail in Lejeune and Wearden (2009), who conclude that sometimes this notion seems to work well, for example, the indifference point can closely track the mean of all the intervals used, as the mean varies, but at other times it works less well. If we assume that all the time intervals used in Edgell (1903) were given equally often, then the mean time intervals for the three participants were 1.72, 1.54, and $1.66 \mathrm{~s}$, in no case very close to the reported indifference point.

In Edgell's second experiment, a short time interval was followed by a longer one, and then the task was to reproduce an interval midway between the two. Both the ratios and the absolute time intervals were varied. Short/long ratios were described sometimes as large (between 1:11 and 1:6.5) and sometimes as small (from 1:3.7 to 1.1:1), and short and long interval ranges were also used. For the long interval ranges, only large ratios were used. For the short interval values the shortest time was $265 \mathrm{~ms}$ and the longest $1,938 \mathrm{~ms}$, for the long interval values, 

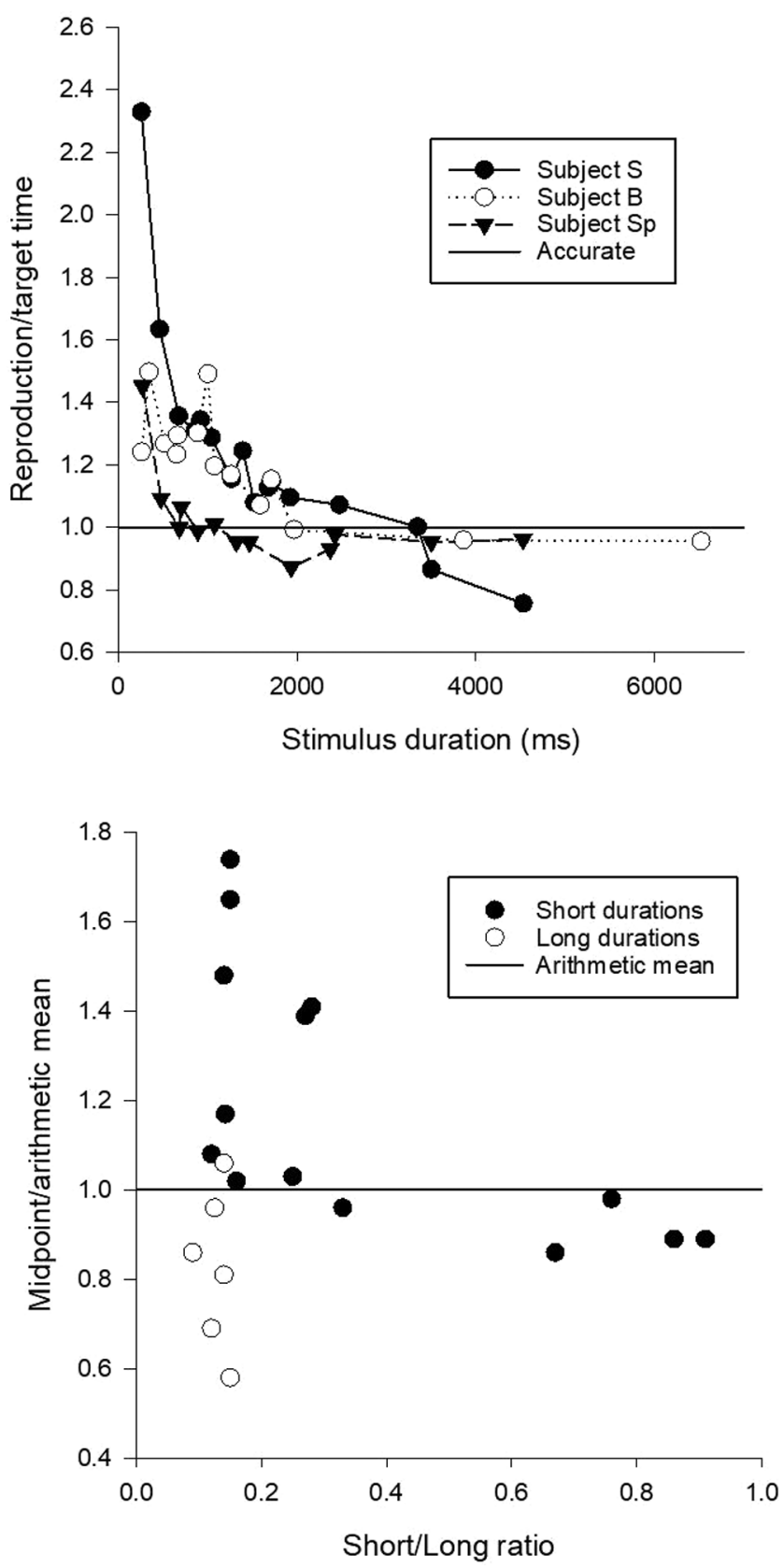

Figure 1. Data from Edgell (1903). Upper panel: Times reproduced by three participants, divided by the target time, plotted against the target time. The horizontal line shows accurate reproduction. Lower panel: The value of the subjective 'midpoint' between two time intervals divided by the arithmetic mean of the intervals, plotted against the ratio of the two intervals used. Data are shown separately for the 'long' and 'short' duration ranges. The horizontal line shows the arithmetic mean. 
the shortest time was $875 \mathrm{~ms}$ and the longest 9,682 ms. The smallest number of observations per condition seems to have been about 20 , but sometimes more were obtained. Data from the two participants were aggregated together, and the data are shown in the lower panel of Fig. 1.

Figure 1 shows the produced midpoint divided by the arithmetic mean of the two times used, so values below 1.0 show a midpoint below the arithmetic mean, and sometimes close to the geometric mean (the square root of the product of the two times). Ratios are shown in terms of the short/long ratio of the two times, so higher values indicate times which are more similar to one another. The data strongly suggest that when the times are short and the short/long ratio is small (i.e., the times are very different) then the midpoint occurs at values above the arithmetic mean. This tendency decreases as the two times become more similar, at which a midpoint below the arithmetic mean can sometimes be noted. In contrast, when the times are long, the midpoint is consistently below the arithmetic mean.

These effects bear some resemblance to those obtained with a bisection task. A common method for studying bisection is to initially present examples of short and long stimulus durations ( $S$ and $L$ ), then a range of durations between them, as well as $S$ and $L$ themselves. The task is to classify each duration in terms of its similarity to $S$ or $L$, using a 'short' or 'long' response. The bisection point is the duration value giving rise to $50 \%$ 'short' and 'long' responses. Early research found effects rather reminiscent of Edgell's results. For example, Wearden (1991) using $S / L$ ratios of $1: 4$ or 1:9 found bisection closer to the arithmetic than geometric mean of $S$ and $L$, particularly in the 1:9 case, whereas Allan and Gibbon (1991), using $S / L$ ratios much closer to 1:1, found below-arithmetic-mean bisection, with most values being close to the geometric mean of $S$ and $L$. However, the analogy between bisection studies and Edgell's work should not be pushed too far, most notably because many factors have been found to affect the bisection point, such as the spacing of durations between a constant $S / L$ pair (Wearden \& Ferrara, 1995). This means that it is perhaps unwise to consider the bisection point as the 'midpoint' between $S$ and $L$. In addition, there are several empirical differences: for one, bisection points well above the arithmetic mean of $S$ and $L$ are very rare; for another, making the durations used in bisection longer does not necessarily produce bisection well below the arithmetic mean (Wearden et al., 1997). Finally, some theoretical models (Kopec \& Brody, 2010) can reconcile arithmetic-mean and below-arithmetic-mean bisection, suggesting that the two are not contradictory.

Edgell's first experiment also bears a resemblance to more recent attempts to identify duration values which are timed with the greatest sensitivity. For example, if people are required to discriminate two durations, are they better able to do this at some time values than others? Grondin (2010) and Unglan and Yagcioglu (2014) both suggest that the answer is yes, and both use a Weber-fraction measure, 
which assesses relative sensitivity. Their procedures are quite complex and will not be discussed here, but Grondin reports that time intervals around $200 \mathrm{~ms}$ are relatively easier to discriminate from one another than those around $1000 \mathrm{~ms}$. Similarly, Unglan \& Yagcioglu (2014) found that intervals around $100 \mathrm{~ms}$ were better discriminated than those either shorter or longer. However, some other recent work suggests that human timing may exhibit more or less constant sensitivity, up until durations of a few seconds, at least, so there is no duration that is relatively more precisely timed than others (Haigh et al., 2021).

\section{Josephine Nash Curtis: The Phenomenology of Time}

Josephine Nash Curtis (1889-1941) received her undergraduate and Master's degrees, in 1910 and 1912, at Wellesley College in Massachusetts, a women-only institution which counts Hilary Clinton among its graduates. She later studied at Cornell University under the supervision of Edward Titchener, being awarded her doctorate in 1915. Curtis then joined the staff of the Boston Psychiatric Hospital, being promoted to the post of Chief Psychologist in 1918, the year she married William Foster, also a former student of Titchener's. Her husband obtained a position at the University of Minnesota, but Curtis was not able to obtain a permanent role there until 1926, the year of her husband's death, when she obtained a post in the Institute of Child Welfare at the university. She worked there until her death, specializing in education and child development.

For a modern reader Curtis (1916) is a highly unusual article. Its 46 printed pages present results from nine series of experiments, mostly involving judgements of the relative duration of two short successively-presented stimuli. The stimuli were usually auditory, but visual stimuli, and non-painful electric shocks, were also used. However, the time judgement data are only briefly presented, and clearly regarded as of secondary importance. "No claim is made for the significance of the numerical results ..." (Curtis, 1916, p. 7). In any case, a potential problem is that the procedures in the experimental series were given in order to the same observers, so carry-over effects (for example, of instructions) from one series to another were very likely.

Curtis's real focus of interest is on the introspections provided by her experimental participants (one of whom was E.G. Boring, later to become famous as a historian of experimental Psychology, see Boring, 1929, for example). Verbatim reports of these introspections take up nearly half the pages of the article, and probably more than half the words, as the introspections are printed in small type.

Why was this a central concern? The reasons lie in a controversy dating from the 19th century, but with resonance today, about whether or not there was a genuine 'time-sense'. Some authors (e.g., Meumann, 1896; Vierordt, 1868) argued that there was, and that duration was a directly perceivable stimulus property like intensity, while others, in Curtis's words (her p. 4) claimed that "duration cannot 
be an original character of sensation", and that time judgements must be derived from something else. Washburn (1903), another notable early female psychologist, said to be the first woman to be awarded a psychology Ph.D. in 1894, also contributed to this debate.

Munsterberg was a particularly prominent advocate of the position that time judgements were secondary or derived. As he puts it (in Munsterberg, 1894, p. 51 ), when discussing estimation of the duration of short intervals, "The subjective measure for such time-lengths, seems to me to lie in sensations peripherally aroused by muscular activity, especially ... reactions [which] occur in the functions of breathing, in voluntary movements of the eyes, limbs, etc." This view was quite widespread in the early years of the twentieth century (e.g., Bourdon, 1907). Curtis's work can be seen as an attempt to exhaustively test, by means of introspection, the idea that mediating movements (or 'kinaestheses') were necessary for the perception of the duration of short intervals of time.

Curtis's extensive use of introspection should come as no surprise given that she was a student of Tichener, who developed his 'structural psychology' with the main aim of determining the contents of mental life through introspection. For a discussion of Titchener's philosophy and methods see Hatfield (2015).

For her studies she used five participants, some of whom were 'highly practiced observers', but one had less experience. Obviously, I cannot present all the details from what is probably around 8,000 words of verbatim introspections here, but certain trends were found in most observers and experiments.

The first finding was the definite presence of mediating activities when people made their initial time judgements, in this case which of two successively-presented tones lasted longer "... chest kinaesthesis has a great deal to do with it. I get a very definite muscular feeling as if I were pressing down inside my chest ....These processes carry the course of the sound ..." (introspection from Bo., E.G. Boring). Others reported humming along with the sound or 'eye kinaesthesis', often associated with visual imagery. However, the second trend was that with more practice the judgements became "almost automatic", and "the deciding seemed to me to be unconscious".

The activities which appeared to initially mediate the time judgements varied from one observer to another, involving voluntary movements of fingers, limbs, or neck, breathing-related sensations, production of sounds, or eye movements that mimicked the duration of the stimuli.

The participants often reported "laying" one time interval over another (particularly when these were of different types, like the filled and unfilled auditory intervals used in Curtis's series two) or "carrying over" the first duration to the second, although they tended to find this more difficult to do when the first time interval was empty rather than the other way around.

In her series 6, Curtis instructed participants "As far as you can, give yourself up passively; let the members [of the pair] impress you passively; do not in any way 
'lay off' the first on the second member" (p. 26). Some observers found this instruction hard to follow, particularly Bo. (Boring) who, Curtis reports, "had always taken the members 'very actively", and claimed that he was sometimes "completely baffled" as to the judgement to make. In general, under passive instructions "strained attention tends to become lower. Subjective certainty and even the determination to judge are less than under active instructions" (p. 32).

One of her summarizing remarks was "we may conclude that, at first, all observers voluntarily institute movements of the body (of the trunk, or head, or arm, etc.). After a small amount of practice, these gross movements disappear, and then all observers report slight, vague strains, usually located in the organ stimulated" (p. 42), so some evidence for Munsterberg's arguments was found, at least early on in the experiments.

Two sorts of later work have echoes of Curtis's investigations. One of these is the Behavioral Theory of Timing (Killeen \& Fetterman, 1988). Reminiscent of the contention of Munsterberg, this argues that animal timing is indirect: animals do not 'time' the durations to which they respond, they just emit a sequence of 'adjunctive behaviours' which fill the duration, and the last member of the adjunctive sequence is a cue for a response which the experimenter measures. This simple idea can be developed in highly ingenious ways (for a discussion see Lejeune et al., 2006, or Wearden, 2016, chapter 9), but one issue that is similar to that treated in Curtis (1916) is whether the adjunctive behaviours are necessary for timing to occur. As Curtis's introspections show, there is little doubt that observers produce behaviours when timing stimuli that could be used to mediate their time judgements, the question is whether these are absolutely necessary. Adjunctive behaviours when animals time their responses definitely do occur (Lejeune et al., 1998), and in some cases may appear to improve timing performance (Safaie et al., 2020), but are they necessary for an accurately timed response? In both cases the answer seems to be no: Curtis's observers could, perhaps after some experience, make their time judgements 'automatically'; Richelle and Lejeune (1980) and Lejeune et al. (1998) conclude, likewise, that adjunctive behaviours are probably not necessary for timed responses to occur, largely on the basis of the fact that adjunctive sequences can be highly variable even when timed responses are not.

The second echo of Curtis's work comes in more recent work on the 'embodiment' of time, the idea that 'body signals' may be involved in the judgement of duration (see Wittmann, 2014, for a discussion). For example, one idea is that "physiological changes form an internal signal to encode the passage of time and the duration of external events" (Wittmann, 2014, p. 511). For a brief review of the possible involvement of heart rate in time judgements see Wearden (2019). In fact, the idea that heart rate or pulse sensations might be involved in time perception has a long history, see, for example, Pavlov (1928). 


\section{Mary Sturt: Development and Discomfort}

Mary Sturt (1896-1994) is now best remembered as an educational psychologist and historian of education. Her best-known work is probably written with Ellen Oakden. She also published a biography of Francis Bacon (the philosopher who was also Lord Chancellor of England at the time of James the First), and abridged versions for children of both the Canterbury Tales and Spencer's Faery Queen. For much of her career she was Vice-principal of St. Mary's College in Bangor, North Wales, an Anglican teacher training college for women.

Her work is more diverse than that of the other two women discussed above. It involved developmental studies of time knowledge, as well as experiments on time perception under conditions of (self-inflicted) discomfort, and some striking observations of performance on standard timing tasks, and time experience under highly stressful conditions.

Mary Sturt's book The Psychology of Time (1925) draws heavily on the content of two articles published in the British Journal of Psychology, Oakden and Sturt (1922) and Sturt (1923), which it reprints almost verbatim. Oakden and Sturt's article is a very extensive investigation of knowledge of everyday time events, such as days, months, seasons, in children. It also involved work on date order, as well as memory for temporal and non-temporal information contained in narratives.

Figure 2 shows some results from Oakden \& Sturt (1922). The upper panel shows correct responses to four questions (from a list of 22) given to children ranging from 4 to 10 years of age. The questions were "what day is it?", "what month is it?", "what time does school start?" and "how long until the school holidays?". Clear developmental trends in terms of accuracy between 4 and 10 years of age can be seen. The lower panel shows results from a problem involving putting historical dates in order: Attila (438 A.D.), Philip of Spain (1585 A.D.), and Nero (50 A.D.). Once again, accuracy improves with age. A common confusion involved number, so "Philip comes first because his number is bigger". Likewise, in another test where Dante (1312 A.D.) was used instead of Philip of Spain, "Nero lived 50 years ago, Dante 1312, therefore Dante lived first".

Another more complex test involved requiring the child to identify 'temporal absurdities', where a temporal marker at one point of a story contradicted one in another part: for example, the narrative began "as the sun was sinking" but characters were about to sit down for "their mid-day meal". Once again, strong developmental trends were present, with children below the age of 10 scoring less than $40 \%$ correct, and those older more than $60 \%$ correct. In other studies children were asked to identify the historical period portrayed in pictures ('Ancient Britons', for example), and in another knowledge of the date order of historical figures was tested.

Oakden and Sturt's article was published in 1922, five years before Piaget's The Child's Conception of Time appeared in French, and 47 years before it appeared in 

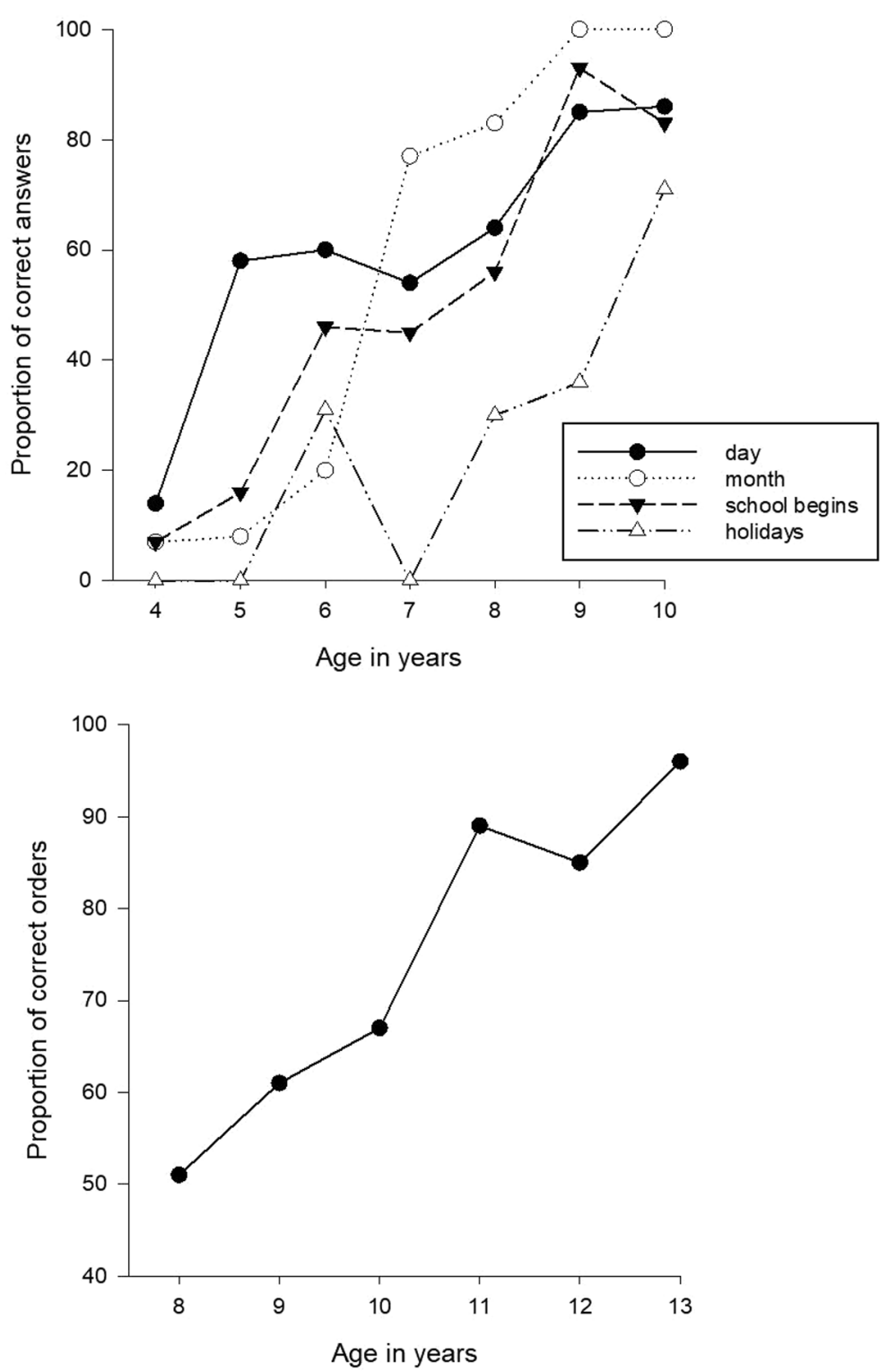

Figure 2. Data from Oakden and Sturt (1922). Upper panel: Percentage of correct responses to four of the questions posed, plotted against the age of the participants. Lower panel: Percentage of correct responses on the date arrangement task (see text for details), plotted against participant age.

English. Piaget (1969) does not refer to Oakden and Sturt's work, yet many of the examples of confusions they give have a definite Piagetian flavour (see Wearden, 2016, chapter 7, for a short discussion of Piaget's book), such as larger date number meaning a longer time ago, as in the example above, an instance of Piaget's 
dictum that, for younger children, "more means more time". However, Sturt's work was not completely ignored, as Cohen et al. (1954, p. 108) described her volume as "the only serious book ... entirely devoted to the psychology of time".

Sturt (1923) reported three experiments on the judgement of duration, from two participants, one of which was herself. These involved estimation of various durations (not given in the text), under different conditions. Perhaps the most striking results are those produced under conditions of discomfort, sometimes involving "a fairly severe burn from a lighted cigarette". In one case this produced marked underestimation of duration (62 and $58 \%$ of the real duration), although in another experiment the judgement was nearly accurate.

Sturt's results from imposing what must have been quite severe pain on herself contrast with a common current view of effects of negative emotions on time perception, where negative events are usually found to make durations appear longer, rather than shorter, as Sturt found (e.g., Droit-Volet \& Meck, 2007). A few recent studies have actually inflicted pain, and threatened it, in timing experiments. For example, Fayolle et al. (2015) found that stimuli predictive of electric shock appeared to last longer than neutral ones. Ogden et al. (2015a) delivered both pleasant (gentle) and unpleasant (painful) touch, at the same time as visual stimuli, and found that the stimuli accompanied by pleasant touch were judged as shorter than those accompanied by unpleasant touch, and stimuli without any tactile stimulation. In Ogden et al. (2015b) participants initially learned to associate different shapes with painful thermal stimulation or no stimulation, then later judged their duration. Stimuli associated with pain were judged as longer than those without this association.

Why did Sturt obtain the opposite effect? One possibility is that her time intervals were much longer than the short ones used in the experiments mentioned in the previous paragraphs (although actual time values are not given in her article), and that for such stimuli the distracting effects of pain diverted attention away from timing, resulting in a shortening of perceived duration. Lake et al. (2016) review the variety of effects that emotion-provoking stimuli may have on time judgements and, in particular, discuss potential differences in results meditated by emotion-based changes in either arousal or attention.

As mentioned above, Sturt's own timing performance was usually inaccurate, but she also reported data from a participant whose judgements of time were exceptionally good, as shown in Fig. 3.

The data in Fig. 3 were produced by a 16-year-old boy who had previously played at guessing three-minute periods "as a means of beguiling the tedium of Latin lessons" (Sturt, 1925, p. 119). There were two basic tasks. The upper panel shows results when the boy estimated various durations without counting; data in the lower panel come from a sort of ratio-setting experiment, where he was asked to divide or multiply various original times by ratios varying from 0.1 to 10 . Performance was remarkably accurate at both tasks. Two other participants, who 

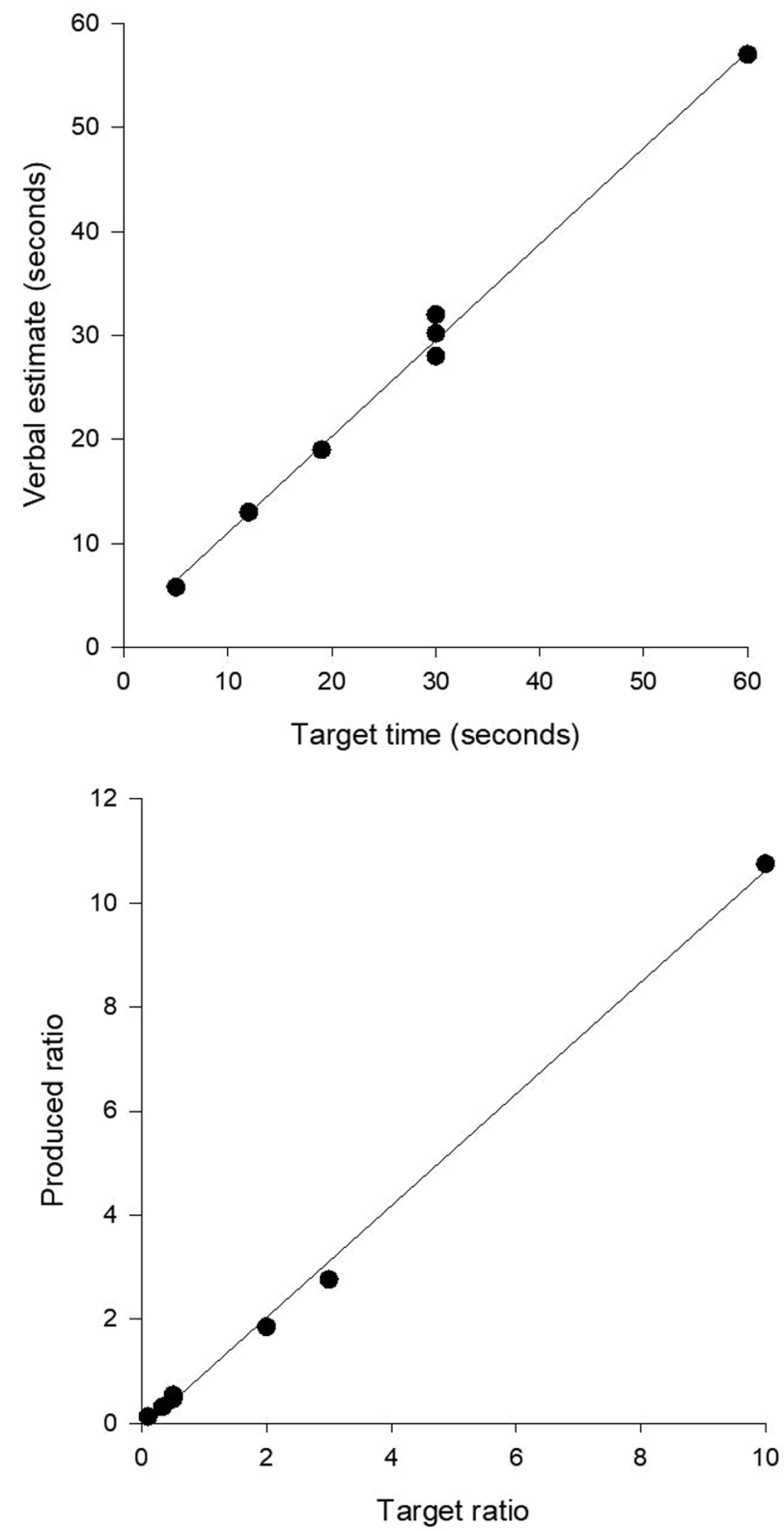

Figure 3. Data from Sturt (1925). Upper panel: Estimation of durations ranging from 5 to 60 s, plotted against real durations. Lower panel: Estimates of ratios of intervals, plotted against real values. 
had no previous experience of estimating time, were much worse at both repeating a time interval, and halving it. Sturt attributes the boy's performance to his superior memory for duration, presumably gained during his Latin lessons.

Sturt (1925) also reports a very striking anecdote from an infantryman fighting on the Somme in 1916, derived from his first experience of "going over the top" under bombardment from the enemy. The soldier laconically remarks "... it would be no exaggeration to describe my feelings as out of the normal." For this soldier, time appeared to be very markedly sped up....

"From the signal of our officers to charge until ... the going down of the sun...the operation appeared to me to last, say half-an-hour, perhaps hardly so much. The sun seemed literally to move visibly in its semi-circle from horizon to horizon" (pp. 9o-91).

In contrast to some recent work, the soldier's report appears to be an unusual instance of a person actually experiencing 'fast time' in a highly arousing situation. Although being distracted from noticing the passage of time, as the soldier must have been, normally makes durations seem short in retrospect (Wearden et al., 2014), reports of feeling that time was passing rapidly during the time period experienced, as in the soldier's observation of the motion of the sun, appear to be very rare. In contrast, experiences of 'slow time' in queues or when bored, seem quite common. Possibly, in order to obtain the phenomenal experience of fast time, the situation which provokes the effect has to be experienced for a substantial period, whereas reports of 'time slowing down' during emergencies generally come from brief events, such as car crashes or falls (Arstila, 2012).

\section{Concluding Comments}

Academic life for women in the early years of the last century was far from easy: even obtaining an undergraduate education, still less a doctorate, was a challenging hurdle that all three women discussed here surmounted. Even when appropriately qualified, progress in academic life was not guaranteed for a woman: Titchener would not allow women, including his own student, Curtis, into his discussion group of 'Experimentalists', and she herself could not initially obtain any university post even with a Cornell doctorate, although her husband with the same qualification did, eventually taking up a position specializing in child welfare. Likewise, Sturt (1925) complains that "facilities for psychological research in this country are so inadequate", and even Edgell, with her two undergraduate degrees, a Master's degree, and two doctorates, spent most of her later career in departmental administration, university management, work on committees, or writing introductory textbooks, rather than developing the career in experimental psychology for which she may have been so suited. Nevertheless, the work which 
they published on time perception offers an insight into the different facets of the subject as investigated in the early years of the twentieth century, and stands as a reminder that women were involved the psychology of time perception even in periods which were unforgiving for them.

\section{Acknowledgements}

The historical research that led to this article was supported by an Emeritus Fellowship grant from the Leverhulme Trust. I am grateful to Professor James Cutting of Cornell University for invaluable help with background information about Josephine Nash Curtis.

\section{References}

Allan, L. G., \& Gibbon, J. (1991). Human bisection at the geometric mean. Learn. Motiv., 22, 39-58. doi: 10.1016/0023-9690(91)90016-2.

Arstila, V. (2012). Time slows down during accidents. Front. Psychol., 3, 196. doi: 10.3389/ fpsyg.2012.00196.

Boring, E. G. (1929). A History of Experimental Psychology. New York, NY, USA: Appleton-Century.

Bourdon, B. (1907). La perception du temps. Rev. Philos. Fr. Etrang., 32, 449-491.

Cohen, J., Hansel, C. E. M. \& Sylvester, J. (1954). An experimental study of comparative judgements of time. Br. J. Psychol., 45, 108-114. doi: 10.1111/j.2044-8295.1954.tb01233.x.

Curtis, J. N. (1916). Duration and the temporal judgment. Am. J. Psychol., 27, 1-46. doi: $10.2307 / 1412852$.

Droit-Volet, S., \& Meck, W. H. (2007). How emotions colour our perception of time. Trends Cogn. Sci., 11, 504-513. doi: 10.1016/j.tics.2007.09.008.

Edgell, B. (1903). On time judgment. Am. J. Psychol., 14, 154-174. doi: 10.2307/1412313.

Edgell, B. (1924) Theories of memory. Oxford, UK: Clarendon Press.

Edgell, B. (1926). Mental life: an introduction to psychology. London, UK: Methuen.

Edgell, B. (1927). Ethical problems: an introduction to ethics for hospital nurses and social workers. London, UK: Methuen.

Edgell, B., \& Symes, W. L. (1906). The Wheatstone-Hipp chronoscope: Its adjustments, accuracy and control. Br. J. Psychol., 2, 58-88.

Fayolle, S., Gil, S., \& Droit-Volet, S. (2015). Fear and time: Fear speeds up the internal clock. Behav. Proc., 120, 135-140. doi: 10.1016/j.beproc.2015.09.014.

Grondin, S. (2010). Unequal Weber fractions for the categorization of brief temporal intervals. Atten. Percept. Psychophys., 75, 1422-1430. doi: 10.3758/APP.72.5.1422.

Haigh, A., Apthorp, D., \& Bizo, L. A. (2021). The role of Weber's law in human time perception. Atten. Percept. Psychophys., 83, 435-447. doi: 10.3758/s13414-020-02128-6.

Hatfield, G. (2015). Objectifying the phenomenal in experimental psychology: Titchener and beyond. Philos. Sci., 19, 73-94. https://doi.org/10.4000/philosophiascientiae.1133.

Killeen, P. R., \& Fetterman, J. G. (1988). A behavioral theory of timing. Psychol. Rev., 95, $274-295$. https://doi.org/10.1037/0033-295X.95.2.274. 
Kopec, C. D., \& Brody, C. D. (2010). Human performance on the temporal bisection task. Brain Cogn., 74, 262-272. https://doi.org/10.1016/j.bandc.2010.08.006.

Lake, J. I., LaBar, K. S., \& Meck, W. H. (2016). Emotional modulation of interval timing and time perception. Neurosci. Biobehav. Rev., 64, 403-420. https://doi.org/10.1016/j.neubiorev.2016.03.003.

Lejeune, H., \& Wearden, J. H. (2009). Vierordt's The Experimental Study of the Time Sense (1868) and its legacy. Eur. J. Cogn. Psychol., 21, 941-960. https://doi.org/10.1080/09541440802453006.

Lejeune, H., Cornet, S., Ferreira, M. A. \& Wearden, J. H. (1998). How do Mongolian gerbils (Meriones unguiculatus) pass the time? Adjunctive behavior during temporal differentiation in gerbils. J. Exp. Psychol. Anim;. Behav. Proc., 24, 352-268. https://doi.org/10.1037/0097-7403.24.3.352.

Lejeune, H., Richelle, M. \& Wearden, J. H. (2006). About Skinner and time: Behavior-analytic contributions to research on animal timing. J. Exp. Anal. Behav., 85, 125-142. doi: 10.1901/ jeab.2006.85.04

Meumann, E. (1896). Beitrage zur Psychologie des Zeitbewusstseins. Philos. Stud., 12, 127-254.

Munsterberg, H. (1894). Studies from the Harvard Psychological Laboratory: (I). Psychol. Rev., 1, 34-60. https://doi.org/10.1037/h0068876.

Oakden, E. C., \& Sturt, M. (1922). The development of the knowledge of time in children. Br. J. Psychol., 12, 309-316.

Ogden, R. S., Moore, D., Redfern, L., \& McGlone, F. (2015a). Touch me for longer this touch feels too short: The effect of pleasant touch on temporal perception. Consc. Cogn., 36, 303-313. https:// doi.org/10.1016/j.concog.2015.07.006.

Ogden, R. S., Moore, D., Redfern, L., \& McGlone, F. (2015b). The effect of pain and the anticipation of pain on temporal perception: A role for attention and arousal. Cogn. Emot., 29, 910-922. https:// doi.org/10.1080/02699931.2014.954529.

Pavlov, M. (1928). Sur le role de l'energie des ondes pulsatiles dans la perception immediate du temps. J. Psychol., 25, 391-424.

Piaget, J. (1969). The child's conception of time. London: London, UK: Routledge.

Richelle, M., \& Lejeune, H. (1980). Time in animal behaviour. Oxford, UK: Pergamon Press.

Safaie, M., Jurado-Parras, M.-T., Sarno, S., Louis, J., Karoutchi, C., Petit, L. F., Pasquet, M. O., Eloy, C., \& Robbe, D. (2020). Turning the body into a clock: Accurate timing is facilitated by simple stereotyped interactions with the environment. Proc. Natl Acad. Sci. U. S. A., 117, 13084-13093. https:// doi.org/10.1073/pnas.1921226117.

Sturt, M. (1923). Experiments on the estimate of duration. Br. J. Psychol., 13, 382-388. https://doi. org/10.1111/j.2044-8295.1923.tb01164.x.

Sturt, M. (1925). The psychology of time. London, UK: Kegan Paul, Trench, Trubner \& Co.

Sturt, M., \& Oakden, E. C. (1926). Modern Psychology and Education. London, UK: Kegan Paul, Trench, Trubner \& Co.

Unglan, P., \& Yagcioglu, S. (2014). Significant variations in Weber fraction for changes in inter-onset interval of a click train over the range of intervals between 5 and 300 ms. Front. Psychol., 5,1453. doi: 10.3389/fpsyg.2014.01453.

Valentine, E.R. (2001). Beatrice Edgell: An appreciation. Br. J. Psychol., 92, 23-36. https://doi. org/10.1348/000712601162086.

Valentine, E. R. (2006). Beatrice Edgell: Pioneer woman psychologist. Hauppage, NY, USA: Nova Science.

Vierordt, K. (1868). Der Zeitsinn nach Versuchen. Tubingen, Germany: Laupp. 
Washburn, M. F. (1903). Notes on duration as an attribute of sensations. Psychol. Rev., 10, 416-422. https://doi.org/10.1037/h0064281.

Wearden, J. H. (1991). Human performance on an analogue of an interval bisection task. Q. Exp. Psychol. B, 43, 59-81. https://doi.org/10.1080/14640749108401259.

Wearden, J. H. (2016). The psychology of time perception. London, UK: Palgrave/Macmillan. doi: 10.1057/978-1-137-40883-9.

Wearden, J. H. (2019). Body temperature and the sense of time: A translation of François (1927) with a commentary. Timing Time Percept., 7, 87-107. https://doi.org/10.1163/22134468-20191142.

Wearden, J. H., \& Ferrara, A. (1995). Stimulus spacing effects in temporal bisection by humans. Q. J. Exp. Psychol. B, 48, 289-310. doi: 10.1080/14640749508401454.

Wearden, J. H., Rogers, P., \& Thomas, R. (1997). Temporal bisection in humans with longer stimulus durations. Q.J. Exp. Psychol. B, 50, 79-94. doi: 10.1080/713932643.

Wearden, J., O'Donoghue, A., Ogden, R., \& Montgomery, C. (2014). Subjective duration in the laboratory and the world outside. In V. Artsila and D. Lloyd (Eds) Subjective time: The philosophy, psychology, and neuroscience of temporality (pp. 287-306). Cambridge, MA, USA: MIT Press.

Wittmann, M. (2014). Embodied time: The experience of time, the body, and the self. In V. Arstila and D. Lloyd (Eds.) Subjective time: The philosophy, psychology, and neuroscience of temporality (pp. 507-523). Cambridge, MA, USA: MIT Press. 